\title{
Effect of Oral Zinc Sulfate on Burning Mouth Syndrome
}

\author{
${\text { Ruman Banik }{ }^{*} \text {, Rubina Shrestha }}^{2}$, Shohda Khatun ${ }^{3}$
}

\section{Abstract}

Introduction: Burning Mouth Syndrome (BMS) is a common condition having a severe burning sensation in the mouth, mainly affects menopausal women and have no definitive treatment so far. The main aim of this study was to evaluate the efficacy of zinc supplement in improving the symptoms of burning mouth syndrome. Materials and Methods: 70 patients were enrolled in this study and were randomly divided in 2 groups. The patients in the intervention group received triamcinolone acetonide topical past with oral zinc sulfate therapy twice daily that continued for 3 months and the patients in the control group receivedtriamcinolone acetonide topical past only. Results: There was a significant difference $(P=0.001)$ in the severity of burning sensation in the two groups after the intervention. Conclusion: Zinc supplement might lessen the intensity of burning mouth syndrome in patients with zinc deficiency.

Keywords: Zinc, Burning Mouth Syndrome, Pain.

Number of Tables: 01; Number of References: 13; Number of Correspondence; 07.

*1. Corresponding Author:

Dr. Ruman Banik, BDS, MS

Medical Officer

Department of Oral and Maxillofacial Surgery

Bangabandhu Sheikh Mujib Medical University (BSMMU), Dhaka.

2. Dr. Rubina Shrestha, BDS, MPH

Former Research Fellow

Nutrition and Clinical Services Division icddrb, Dhaka.

3. Prof. Shohda Khatun, BDS, MS

Professor

Department of Oral and Maxillofacial Surgery

Bangabandhu Sheikh Mujib Medical University (BSMMU), Dhaka.

\section{Introduction:}

Burning mouth syndrome (BMS) is a chronic pain disorder characterized by burning, stinging, and/or itching of the oral cavity in the absence ${ }^{1-2}$. Burning sensation usually felt in the normal oral mucosa, especially on the tongue, which affects other mucosal surfaces, including the lips, buccal mucosa and the floor of the mouth ${ }^{3}$.The tongue is found to be the most common location for burning sensation in the oral cavity. BMS can be accompanied by Dysgeusia (distortion in sense of taste), Glossodynia (painful tongue), Glossopyrosis (burning tongue) \& Xerostomia (dry mouth the symptoms include a burning sensation, occasional pain, taste disturbances. Burning sensation is mostly reported in postmenopausal women ${ }^{4}$. The most commonly affected area is tip of the tongue and also affects the lips, gingiva and palate. The condition is extremely rare in patients under 30 years and never been reported in children and adolescence ${ }^{5}$. The exact etiology of BMS is unknown. Although there is no definitive cause of primary BMS, there are numerous potential secondary causes of the burning mouth syndrome. Several factors play an important role in the etiology of BMS. These are grossly classified to local, systemic and psychological factors ${ }^{6}$. After Iron, Zinc is the 2nd most important element of the body, which enhances growth and development. Though zinc deficiency has been reported to be related to BMS in the immune system, the beneficial effects of zinc replacement therapy has not been evaluated in patients with BMS. A study conducted by Cho in 2010 concluded that $26.8 \%$ of patients with BMS exhibited zinc deficiency and zinc replacement therapy experienced a decrease in burning sensation ${ }^{7}$. A burning sensation may also occur in other oral diseases like lichen planus and geographic tongue ${ }^{8}$. Burning mouth syndrome is associated with nutritional deficiencies including vitamin B1, B2, B6 and B12 deficiencies. Though, some studies have shown that zinc deficiency can also lead to BMS. Recent diagnostic criteria include continuous everyday pain in the oral cavity in association with normal oral mucosa after excluding other local and systemic diseases ${ }^{9}$. Metabolic endocrine and nutritional disorders may also lead to BMS. Some nutritional disorders, such as deficiencies in iron, zinc and vitamin $\mathrm{B}$ group, especially vitamin B12 $2^{10-11}$. The early diagnosis of BMS is based on the exclusion of etiologic factors. Significant clinical recovery from BMS is possible only when systemic, local and psychological factors are treated or their eliminated ${ }^{12}$.

\section{Objectives}

This study was conducted to evaluate the effect of zinc replacement therapy on BMS symptoms.

\section{Materials and Methods:}

This clinical trial study was conducted in oral and maxillofacial surgery department, Bangabandhu Sheikh Mujib Medical University (BSMMU), Dhaka between January 2015 and August 2016. Patients with BMS and who had zinc deficiency in laboratory evaluations, were included in the study. We performed a complete blood count $(\mathrm{CBC})$ and serum zinc. Burning sensation in all or some parts of the oral cavity with or without symptoms subjects were divided to case and control groups. All the study population were examined before treatment and the burning severity was evaluated based on numeric rating scale (NRS), with ' 0 ' indicating there is absent of 
burning sensation and ' 10 ' indicating the most severe burning sensation experienced by the study subject. Study subject was asked to determine the severity of their burning sensation from 0 to 10 . The patients in the case group were treated with zinc sulphate were administered twice daily and the zinc therapy was continued for three months. In the control group placebo were administered two times daily for three months. After three months, burning sensation severity was evaluated and measured. The serum zinc levels were determined and if these levels were not normal, treatment with zinc sulfate capsules continued for another month. After this period, the subjects were evaluated again and burning sensation severity was determined. After the study, the control group patients also received zinc replacement therapy. Data were analyzed with the SPSS software. The t-test was used to evaluate the means of burning sensation scores and serum zinc levels of the subjects.

\section{Results:}

In the present study, 70 patients with BMS, who had zinc deficiency, were evaluated, with 35 subjects in the case and 35 in the control groups. In the case group, there were 32 females and 3 males; in the control group, there were 30 females and 5 males. The mean age of the subjects were 43 \pm 5.02 and $45.6 \pm 7$ years in the case and control groups, respectively, with no statistically significant differences between the two groups. The mean durations of BMS were $2 \pm 0.50$ and $3.1 \pm .54$ years in the case and control groups, respectively, with no statistically significant differences between the two groups. Before intervention there was no difference in sensation severity and serum zinc level between the groups. At the end of the study there was a significant difference in sensation severity and serum zinc level between the two groups.

Table-I: Severities of Burning Sensation and Serum Zinc Levels Before and After Treatment $(n=30)$.

\begin{tabular}{lccc}
\hline & $\begin{array}{c}\text { Case } \\
(\mathbf{n}=\mathbf{3 5}) \\
\mathbf{n}(\%)\end{array}$ & $\begin{array}{c}\text { Control } \\
(\mathbf{n}=\mathbf{3 5})\end{array}$ & p-value \\
$\mathbf{n}(\%)$ & \\
\hline Burning sensation before the intervention & $5.6 \pm 1.3$ & $4.9 \pm 1.1$ & 0.05 \\
Burning sensation after the intervention & $1.4 \pm 0.9$ & $4.9 \pm 0.69$ & 0.001 \\
Serum zinc level before the intervention, g/dl & $60 \pm 10.5$ & $62 \pm 8.05$ & 0.4 \\
Serum zinc level after the intervention, g/dl & $83 \pm 0.92$ & $65 \pm 2.38$ & 0.008 \\
\hline
\end{tabular}

t-test was used to evaluate the means of burning sensation scores and serum zinc levels of the subjects

\section{Discussion:}

The results of this study showed that zinc supplementation lessen the severity of burning sensation in patients with BMS. Although the short term follow up studies show potential symptomatic improvement with treatment in patients with BMS, the long-term outcomes for BMS remain unclear. There is an important role of Zinc in the growth and development of the immune system and the neurologic functions. Zinc deficiency also affect the immune system and the repair processes of the mucosa and may cause BMS. Another study conducted by Maragou P et al showed lower serum levels of zinc in patients with BMS compared to healthy subjects ${ }^{13}$. Pekiner conducted a study in 2009 in 30 BMS patients and 30 healthy subjects and compared salivary levels of magnesium, zinc and copper among them and reported there were no significant differences between the two groups4. In a study of Cho et al. in 2010, 20 rats were divided to two groups of 10, where one group received a zinc deficient diet and the other group received a standard diet. After 20 weeks, hyperkeratosis and an increase in mitotic activity were observed in the dorsum area of the tongue of rats receiving the $\mathrm{Zn}$-deficient diet. It is not possible to compare the results of the present study with those of other studies from a clinical point of view due to the limited number of studies on BMS serum zinc levels.

\section{Conclusion:}

The results of the present study concluded that zinc supplement reduces the symptom in patients with BMS.

\section{Conflict of Interest: None.}

\section{Acknowledgement:}

Patients who willingly participated in this study, other Professors and fellow colleagues of the Oral and Maxillofacial Surgery department, Bangabandhu Sheikh Mujib Medical University (BSMMU), Dhaka.

\section{References:}

1. Netto FO, Diniz IM, Grossmann SM, de Abreu MH, do Carmo MA, Aguiar MC. Risk factors in burning mouth syndrome: a case-control study based on patient records. Clin Oral Investig. 2011; 15: 571-575.

https://doi.org/10.1007/s00784-010-0419-5

PMid:20440632

2. Lamey PJ, Lamb AB. Prospective study of aetiological factors in burning mouth syndrome. Br Med J (Clin Res Ed). 1988; 296:1243-1246.

https://doi.org/10.1136/bmj.296.6631.1243

PMid:3133028 PMCid:PMC2545712

3. Pezelj-Ribaric S, Kqiku L, Brumini G, Urek MM, Antonic R, Kuis D, et al. Proinflammatory cytokine levels in saliva in patients with burning mouth syndrome before and after treatment with low-level laser therapy. Lasers Med Sci. 2013; 28(1): 297-301.

https://doi.org/10.1007/s10103-012-1149-5

PMid:22773117

4. Pekiner FN, Gumru B, Demirel GY, Ozbayrak S. Burning mouth syndrome and saliva: detection of salivary trace elements and cytokines. J Oral Pathol Med. 2009; 38(3): 269-75.

https://doi.org/10.1111/j.1600-0714.2008.00734.x

PMid:19141055

5. Grushka M, Epstein JB, Gorsky M. Burning mouth syndrome: differential diagnosis. Dermatol Ther. 2002; 15: 287-291.

https://doi.org/10.1046/j.1529-8019.2002.01535.x 
6. Therapeutic options in idiopathic burning mouth syndrome: literature review. Int Arch Otorhinolaryngol. 2015; 19(1): 86-9.

7. Cho GS, Han MW, Lee B, Roh JL, Choi SH, Cho KJ, et al. Zinc deficiency may be a cause of burningmouth syndrome as zinc replacement therapy has therapeutic effects. J Oral Pathol Med. 2010; 39(9): 722-7.

https://doi.org/10.1111/j.1600-0714.2010.00914.x

\section{PMid:20618611}

8. Lamey PJ, Lamb AB. Prospective study of aetiological factors in burning mouth syndrome. Br Med J (Clin Res Ed). 1988; 296(6631):1243-6.

https://doi.org/10.1136/bmj.296.6631.1243

PMid:3133028 PMCid:PMC2545712

9. Gurvits GE, Tan A. Burning mouth syndrome. World J Gastroenterol. 2013; 19(5): 665-72. https://doi.org/10.3748/wjg.v19.i5.665

PMid:23429751 PMCid:PMC3574592

10. Mock D, Chugh D. Burning mouth syndrome. Int J Oral Sci. 2010; 2(1): 1- 4.

https://doi.org/10.4248/JOS10008

PMid:20690412 PMCid:PMC3475590

11. Muzyka BC, De Rossi SS. A review of burning mouth syndrome. Cutis. 1999; 64(1): 29-35.

12. Sun A, Wu KM, Wang YP, Lin HP, Chen HM, Chiang CP. Burning mouth syndrome: a review and update. J Oral Pathol Med. 2013; 42(9): 649-55.

https://doi.org/10.1111/jop.12101

PMid:23772971

13. Maragou P, Ivanyi L. Serum zinc levels in patients with burning mouth syndrome. Oral Surg Oral Med Oral Pathol. 1991; 71(4): 447-50.

https://doi.org/10.1016/0030-4220(91)90427-E 